\title{
Análisis contrastivo de la expresión de la evidencialidad en serbio y español
}

Palabras clave: análisis contrastivo serbio/español, evidencialidad, modalidad, marcadores evidenciales.

\section{Consideraciones generales}

Marcar la fuente de la información presentada por un enunciado constituye una de las estrategias más importantes de la comunicación humana. En un artículo de la prensa, en una escritura académica o en una conversación cotidiana, es decir, en cualquier tipo de la realización textual, aparece una serie de elementos lingüísticos que especifican el carácter epistemológico del discurso, haciendo referencia al origen de la información y al modo en el cual ha sido obtenida. Algunas lenguas codifican este contenido informativo mediante los recursos morfológicos, los afijos flexivos desarrollados por el sistema, otras lo hacen por medios léxicos, sintácticos o discursivos, utilizando determinados verbos, adverbios parentéticos, expresiones de tipo según las fuentes / palabras, dicen, etc. o cláusulas con verbos de percepción. En efecto, tomen la forma que tomen, se trata de unidades que le permiten al hablante de cada lengua dar pruebas o 'evidencias' de la información comunicada y evaluar el grado de su certeza y veracidad. De ahí que en la tradición lingüística anglosajona se haya acuñado, a partir del significado de la palabra evidence $^{1}$, el término evidentiality (evidencialidad), con el cual se designa el dominio semántico relacionado con la codificación de la referencia al origen de la información.

1 Evidence: Ground for belief; testimony or facts to prove or disprove any conclusion. The Oxford English Dictionary volumen V, 1989. 
En el presente trabajo la evidencialidad se plantea a partir de un enfoque interlingüístico que nos permite cotejar la organización de los sistemas evidenciales en serbio y español, identificar sus rasgos comunes y distintivos y, por último, facilitar una visión comparativa de las formas empleadas en cada lengua. La base del análisis será un corpus formado por ejemplos recogidos del Corpus de la lengua serbia contemporánea (SrpKor), así como del Corpus de referencias del español actual (CREA). Dado el carácter contrastivo del estudio, se examinan en detalle diferentes posibilidades de traduccioń de todas las expresiones lingüísticas con valor evidencial, tanto en su realización léxica y gramatical como en la discursiva.

\section{Estudios sobre la evidencialidad}

Dar una explicación coherente y uniforme de la evidencialidad no es tarea fácil, ya que se trata de un fenómeno cuyas realizaciones formales pueden variar considerablemente de una lengua a otra, tanto según el número de fuentes de información codificadas, como según los modos de su expresión, es decir, según la complejidad de las formas (Aikhenvald 2004: 23).

Chafe (1986) sugiere distinguir dos enfoques en la interpretación de la evidencialidad: un enfoque restringido y otro amplio. La diferencia estriba en los parámetros que se toman en consideración: en el primer caso se insiste en las evidencias sobre las cuales reside el mensaje, mientras que, en el segundo, el estudio se centra en su estatus epistemológico que, a través de valores subjetivos (conjeturales, dubitativos y de probabilidad), puede implicar valores evidenciales en las lenguas sin evidencialidad codificada morfológicamente.

Según el enfoque restringido, que proponen Willett (1988) y Aikhenvald (2004), la evidencialidad se considera categoría estrictamente gramatical con referencia a la fuente de la información. Así concebida es un rasgo propio sólo de un limitado número de lenguas.

El enfoque amplio ha surgido a partir de los estudios realizados sobre las lenguas indoeuropeas, que carecen del paradigma formal. Atendiendo a un criterio más flexible y al repertorio de las formas que puedan adoptar esas lenguas, la evidencialidad representa una de las manifestaciones de la actitud epistémica (Palmer, 1986; Chafe, 1986) ya que el hablante, al citar las evidencias, expresa implícitamente el grado de compromiso frente al contenido presentado por el discurso. En otras palabras, la evidencialidad y la modalidad se encuentran en una relación de 'inclusión', o sea, un concepto aparece incluido 
dentro del alcance de otro (Dendale \& Tasmowsky, 2001: 342). Interpretada desde una perspectiva amplia, la evidencialidad no supone sólo la referencia a la fuente de la información obtenida directa o indirectamente, sino que forma parte de un dominio semántico más extenso, relacionado con el conocimiento y las creencias del hablante, esto es, con su expresión de duda, conjetura, probabilidad o de cualquier tipo de postura o estimación personal.

Resumiendo, se podría trazar una línea divisoria entre la evidencialidad como categoría gramatical y la evidencialidad como concepto semántico. La diferencia en la interpretación depende de los datos empíricos que se tomen en consideración. Las lenguas que marcan la evidencialidad de forma sistemática y con morfemas obligatorios, dan lugar a un enfoque restringido, según el cual dicho fenómeno se reduce a una categoría estrictamente gramatical con referencia a la fuente de la información. Sin embargo, desde la perspectiva de la mayoría de las lenguas indoeuropeas, donde tienen cabida el serbio y el español, el término evidencialidad cubre un área más extensa de lo que es la expresión de la evidencia en sí, constituyendo un dominio semántico-pragmático relacionado con la modalidad epistémica.

\section{Recursos lingüísticos evidenciales en serbio y en español}

En serbio, al igual que en la mayoría de las lenguas eslavas (con la excepción de búlgaro y el macedonio), la evidencialidad no aparece gramaticalizada morfológicamente, lo que no quiere decir que no existan otros medios de codificación. Cuando un dominio semántico no se cubre con los morfemas gramaticales, la lengua los substituye por otros recursos o desarrollando diferentes estrategias: es decir, se sirve de medios léxicos o sintácticos o se apoya de un proceso discursivo, siendo en este último caso la información contextual una condición imprescindible para la interpretación de los enunciados. En concreto, en determinadas circunstancias contextuales las categorías de tiempo en español y de tiempo y aspecto verbal en serbio se convierten en medios adecuados para la expresión de distintas características del significado evidencial.

\subsection{La expresión de la evidencialidad en serbio y formas equivalentes en español}

La función de un marcador evidencial la pueden desempeñar las siguientes categorías léxicas y gramaticales: 
- adverbios oracionales,

- el tiempo verbal,

- el aspecto verbal,

- la oración subordinada completiva con verbos de percepción,

- los verbos činiti y izgledati (parecer),

- la construcción mora da (debe de) + el verbo en forma finita; biće da (será que).

\subsubsection{Los medios léxicos: los adverbios navodno, tobože, očigledno}

El marcador navodno tiene un significado próximo al adverbio español supuestamente. De acuerdo con su etimología (el verbo navoditi significa 'citar') presenta el enunciado como una cita o reproducción de palabras ajenas, de modo que lo podemos substituir por la expresión prema navodima / prema rečima drugib (según las citas / según palabras de otros) o por los verbos de lengua kažu (dicen), priča se (se cuenta). Al usar este adverbio, el hablante atribuye la afirmación a una tercera persona o a rumores, es decir, a una fuente indeterminada, tal y como ilustran los siguientes ejemplos:

(1) Novinama nije verovao, jer navodno greše. [SrpKor]

No creía lo que dicen los periódicos, porque supuestamente / según decía /se equivocan mucho.

Postoje programi koji, navodno, pripremaju mozak mališana da jednog dana lakše pamti strane jezike. [SrpKor]

Existen programas que, según dicen, preparan el cerebro de los niños para memorizar más fácilmente lenguas extrajeras.

Frente a éste, caracterizado por un significado predominantemente evidencial, el marcador tobože (aparentemente) tiene un valor de alcance más amplio. Puede presentar hechos, eventos o situaciones a partir de evidencias indirectas, con lo que se acerca a las expresiones parece o según parece como en

(2) Godine 1995 on je, tobože, otišao u penziju zato što je oboleo od kancera. [SrpKor]

En 1995, según parece, se jubiló porque estaba enfermo de cáncer.

O bien manifestar incredulidad o duda respecto al contenido proposicional, expresada a veces en un tono irónico. Empleado así, tobože adquiere valor 
citativo, acercándose al significado del adverbio supuestamente, como señala el siguiente ejemplo

(3) Neće doći. Tobože je bolestan.

No va a venir. Aparentemente está enfermo. (Se puede parafrasear: "Lo ha dicho, pero yo no le creo").

La diferencia entre estos adverbios consiste en que navodno, el menos marcado, remite sólo a la fuente de la información, es decir, cita palabras ajenas, mientras que tobože, de valor fundamentalmente modal, es más ambiguo y, por lo tanto, más dependiente del contexto. Este adverbio puede desarrollar cierto matiz evidencial dentro de una situación comunicativa concreta, en particular, si el hablante da a entender que con el enunciado (en este caso con Aparentemente está enfermo) comenta las palabras de otra persona, expresando rechazo, desaprobación o una actitud irónica frente a ellas.

A diferencia de los mencionados, el marcador očigledno, equivalente en español al adverbio evidentemente refuerza valor asertivo y presenta el contenido proposicional, de la oración en que aparece, como algo seguro e incuestionable, por lo que es incompatible con construcciones que codifiquen percepción directa (de la que nos ocupamos en el siguiente apartado). En efecto, el adverbio očigledno es marcador de evidencialidad inferencial, tal como ilustra

(4) Znao je da nije tako: kad mu je predala papirić, bila je nesumnjivo uzbuđena. Očigledno se bila raspametila od straha. [SrpKor]

Sabía que no era así: cuando le entregó el papelito, indudablemente estaba nerviosa. Evidentemente se había desquiciado de miedo.

La percepción del hablante de que la persona en cuestión «se había desquiciado de miedo» es resultado de una inferencia, originada a partir de unos indicios observables de la oración «estaba nerviosa». Očigledno o evidentemente en la versión española refuerzan la argumentación del contenido expresado en el enunciado anterior, haciéndola más firme y aceptable para el interlocutor.

\section{1.2 Las categorías verbales de tiempo y aspecto}

Las categorías de tiempo y aspecto, a partir de sus funciones básicas y en combinación con parámetros contextuales y situacionales adecuados, pueden codificar diferentes aspectos del significado evidencial. En concreto, los verbos imperfectivos en presente y el aoristo marcan evidencialidad directa, mientras que el perfecto adquiere un valor evidencial de carácter deductivo. 
El presente de verbos imperfectivos es un marcador cero, tanto en serbio como en español, es decir, el significado evidencial no se realiza mediante un índice específico sino por el mismo hecho de proferir la aserción. Así los enunciados

(5)Deca se igraju.

Los niños están jugando.

Duva vetar i lije kiša.

Hay viento y llueve a cántaros.

pueden obtener una lectura evidencial siempre y cuando el acto de la enunciación coincida con el acto de percibir la realidad. Si el hablante informa sobre los hechos a los cuales tiene acceso directo, es suficiente referir a ellos, para dar a entender, basándose en la situación comunicativa, que la información procede de su experiencia personal, o sea, de su observación directa.

El aoristo es un tiempo de pasado con muchos valores atípicos. Sin entrar en los detalles sobre su uso, se pueden mencionar, para los fines de este trabajo, dos funciones esenciales. Es una forma que señala: 1) eventos y situaciones acabadas en el pasado, por lo que se suele emplear en la narración, a la que proporciona dinámica, expresividad y cierto tono dramático; 2) eventos acontecidos en un pasado próximo, a veces inmediatamente anterior al acto de habla. El primer uso es equivalente al pretérito perfecto simple, mientras que el segundo corresponde, dependiendo de las expresiones adverbiales que lo acompañen, al pretérito perfecto compuesto o a la perífrasis acabar de + infinitivo, como demuestran los siguientes ejemplos:

(6)Mašinista zviznu (aoristo), voz krenu (aoristo) i brzo nestade (aoristo), mešajući svoj beli dim sa snežnim vihorom. [SrpKor]

El maquinista silbó, el tren salió y desapareció rápidamente, mezclando su humo blanco con la ventisca.

Malopre vam rekoh (aoristo) da ne razumem njen postupak. [SrpKor]

Acabo de decirle que no entiendo su comportamiento.

La expresión del significado evidencial se asocia al segundo uso: su relación con el tiempo presente, es decir, su proximidad al momento de la enunciación permite que lo dicho en aoristo se presente como una situación vista o experimentada desde la perspectiva del hablante. Así, una aserción 
(7)Ispade (aoristo) ti novčanik.

Se te ha caído el monedero.

además de describir lo ocurrido, señala que el evento se ha realizado dentro del espacio perceptivo del hablante, que él mismo lo ha experimentado, o sea, percibido visualmente. El aoristo es semántica y gramaticalmente incompatible con el estilo indirecto, ya que la distancia frente a lo dicho y el cambio de perspectiva, que éste conlleva, se oponen a la «experiencialidad» (a su capacidad de referir a la fuente directa), tan propia de esta forma verbal. En consecuencia, una oración en estilo indirecto con aoristo resulta agramatical, por lo que éste, en la transposición de un enunciado directo al indirecto, debe ser substituido por el perfecto:

(8)Kaže da ti *ispade (aoristo) / je ispao novčanik (perfecto) novčanik.

Dice que se te ha caído el monedero.

A veces los límites entre la evidencialidad directa y la evidencialidad inferencial resultan muy borrosos, de modo que un mismo enunciado se puede interpretar, dependiendo de los parámetros contextuales, de dos maneras diferentes. Así El profesor está aquí puede señalar una información que estriba en la percepción visual o bien una información obtenida por un proceso de inferencia a partir de hechos extralingüísticos (por ejemplo, las cosas del profesor que confirman su presencia). La distinción se puede establecer mediante el uso del marcador evidentemente: la evidencialidad directa no es compatible con este adverbio mientras que la inferida sí lo es: Evidentemente (juzgando por indicios externos) el profesor está aquí.

La evidencialidad de tipo inferencial, como ya se ha señalado, está relacionada con el uso del perfecto. En serbio es una forma de pasado no marcada, es decir, desprovista de la referencialidad, de modo que puede cubrir el uso de cuatro formas del pasado en español: el pretérito perfecto simple, el pretérito perfecto compuesto, el pretérito imperfecto y el pretérito pluscuamperfecto. Uno de sus significados básicos es presentar los eventos acabados en el pasado, pero relevantes en el momento del habla, es decir, relacionar acciones o situaciones pasadas con sus resultados o consecuencias actuales. La codificación del valor evidencial se vincula justamente con este significado resultativo. Así, la selección del perfecto formado por verbos imperfectivos adquiere un matiz claramente inferencial, mientras que el perfecto de verbos perfectivos marca la evidencialidad directa, como demuestran los siguientes ejemplos: 
(9)Neko je ulazio (verbo imperfectivo en perfecto) u kuću.

Alguien ha entrado / ha estado entrando en casa. (Se ven las huellas).

Neko je ušao (verbo perfectivo en perfecto) u kuću.

Alguien ha entrado en casa. (Se ha oído la puerta o se ha visto a alguien entrando en casa).

Las formas que funcionan como marcadores de evidencialidad inferida pueden comparecer con los adverbios očigledno y su sinónimo očito (evidente), o con las expresiones po svemu sudeći (a juzgar por todo), izgleda (parece), etc.: Evidentemente / a juzgar por las buellas / parece que alguien ba entrado / ba estado entrando en casa. Sin embargo, resulta inapropiado utilizarlos si lo ocurrido ha tenido lugar dentro del espacio perceptivo del hablante, es decir, si lo dicho viene derivado de su percepción visual o auditiva.

\subsubsection{Oración subordinada completiva con verbos de percepción}

Además de los recursos léxicos y las categorías verbales de tiempo y aspecto, las oraciones subordinadas completivas con verbos de percepción pueden obtener diferentes interpretaciones evidenciales, lo que depende de la clase de complemento que seleccionen. Los verbos imperfectivos de percepción física, gledati (mirar) posmatrati (observar), y slušati (escuchar), requieren como complementos entidades o situaciones concretas y, además, exigen el uso del nexo kako (como). Así empleados sugieren que el hablante tiene acceso directo a lo que es objeto de su percepción:

(10)Gledam kako golubovi lete nad selom, u krug. [SrpKor]

Miro como las palomas sobrevuelan el pueblo, en círculos.

Volim da slušam kako svira. [SrpKor]

Me gusta escuchar como toca.

Frente a éstos, los verbos biaspectuales videti (ver) y čuti (oir) admiten complementos de dos clases: aquellos que designan tanto entidades concretas como abstractas. Cuando se usan en su significado literal, como verbos de percepción física, seleccionan el nexo kako (como) y marcan el acceso directo a la información: 
(11)Vidim kako se zidovi ruše. Kako pada plafon. [SrpKor]

Veo como las paredes se están derrumbando. Como se cae el techo.

Čujem te reči. Čujem kako ih mirno i sabrano izgovara. [SrpKor]

Oigo estas palabras. Oigo como las pronuncia tranquila y cuidadosamente.

En efecto, los verbos de percepción en los ejemplos (11) sólo nombran explícitamente el acto de percibir, intensificando el significado evidencial que, como ya he explicado, en el caso de la percepción directa, no tiene una realización gramatical específica.

Sin embargo, el cambio del complemento origina un proceso de metaforización, de modo que videti (ver) desde un dominio concreto de experiencia sensorial se transfiere a un dominio cognitivo y se convierte en un verbo de percepción mental. Cuando se emplea en sentido figurativo, selecciona el nexo da (que) e induce al significado evidencial, aludiendo a que la información ha sido adquirida a partir de una actividad cognitiva, tal y como se observa de

(12) Ne, nemam prijatelja, tek sad vidim da ih nemam. [SrpKor]

No, no tengo amigos, sólo ahora veo que no los tengo.

donde el verbo videti (ver) conlleva el significado «ver con ojos interiores» o comprender la situación a partir del conocimiento o, en este caso concreto, llegar a la conclusión a partir del comportamiento de la gente.

Asimismo el verbo čuti (oír), seguido del nexo da (que), pierde su carácter perceptual y se convierte en marcador de evidencialidad indirecta, o más precisamente, remite a una información transmitida de segunda mano. Así

(13)Čujem da ti je žena pobegla. [SrpKor]

Literalmente: Oigo que se te ha escapado la mujer.

se podría parafrasear He oído que la gente dice que se te ha escapado la mujer o Me be enterado de que se te ba escapado la mujer.

Como ya he señalado en el apartado anteriror, no se puede establecer siempre una clara distinción entre la evidencialidad perceptual y la evidencialidad inferida, sin recurrir al contexto. Así los siguientes enunciados 
(14 a.) Neću da smetam, vidim da uči.

No quiero molestar, veo que está estudiando.

(14 b.) Vidim da uči. Sve ispite je položila.

Veo que estudia. Ha aprobado todos los exámenes.

se puede interpretar, en serbio, como una información, derivada de la percepción directa (14 a.) o como una inferencia (14 b.).

Esta ambigüedad se puede evitar en español con el uso de la perífrasis: Veo que está estudiando que tiene un referencia clara al acceso perceptual. Además, tanto en serbio como en español, la ambigüedad desaparece cuando no hay concurrencia temporal entre el verbo de percepción y el predicado de la oración subordinada: Vidim da si učio (Veo que has estudiado) señala una información obtenida por inferencia.

\subsubsection{Los verbos činiti se e izgledati (parecer)}

Estos verbos, ambos equivalentes a parecer, integran en su significado rasgos epistémicos y evidenciales. Por un lado expresan cierta reserva o precaución del hablante con respecto al contenido proposicional, por otro, señalan su origen perceptual o inferencial, es decir, presentan el enunciado como un supuesto o juicio basado en evidencias, accesibles al hablante mediante los sentidos o bien a partir de su razonamiento sobre la realidad. El predominio de un matiz u otro depende del contexto, como se puede observar de

(15 a.) Čini se da se tako nešto ne može i ne sme ponoviti. [SrpKor]

Parece que algo así no puede ni debe repetirse.

(15 b.) Uspeh je, čini se, bio polovičan. [SrpKor]

El éxito, según parece, ha sido parcial. (El hablante juzga por lo que ha dicho la crítica o por la reacción del público)

(16 a.) On, koji je uvek bio veseo i smiren, sad mi izgleda vrlo nervozan i jako uzrujan.

Él, que siempre ha sido alegre y tranquilo, ahora me parece muy nervioso seriamente perturbado. 
(16 b.) Izgleda da mu je strah oduzeo moć govora. [SrpKor]

Parece que el miedo le ha quitado el poder de hablar.

El uso de estos verbos disminuye el carácter asertivo del enunciado: el hablante expone los hechos, pero con cierta distancia o precaución con respecto a su certeza. Aunque son sinónimos desde el punto de vista léxico, se diferencian por los rasgos funcionales y los efectos pragmáticos que produce su uso.

Činiti se, empleado siempre en forma impersonal, presenta el enunciado como un supuesto o juicio que ha surgido de un proceso inferencial. El hablante enuncia o, mejor dicho, deduce que «algo así no se puede ni debe repetir» (ejemplos 15 a.), partiendo de una serie de datos, presentes físicamente en su entorno o apoyándose en el conocimiento que posee sobre el asunto en cuestión. Sin embargo, cuando ocupa la posición parentética ( 15 b.), admite una lectura más libre, la cual, por supuesto, no excluye su significado básico: en este caso čini se se aproxima al marcador según parece o según dicen, o sea, se podría presuponer, dentro de un contexto muy específico, que la información procede de una fuente hablada o escrita.

Frente a éste, el verbo izgledati (parecer) puede tener distintos valores (perceptuales e inferenciales), dependiendo del complemento que lo acompañe. Debido a su relación semántica con el verbo de la misma raíz gledati (mirar), empleado como verbo copulativo con un adjetivo en función del atributo, implica que lo dicho procede de una percepción visual, como se observa de ( 16 a.): el hablante mismo es el que percibe las propiedades y expresa su impresión. Sin embargo, si se emplea con una oración subordinada (16 b.), izgleda $d a$ (parece que), predomina el valor inferencial, es decir, el enunciado se interpreta como resultado de un proceso de razonamiento, basado en diferentes clases de evidencias.

Los dos verbos suelen aparecer con el dativo del pronombre personal: Čini mi se neverovatnim (Me parece increíble) e Izgleda mi vrlo nervozan (Me parece muy nervioso). La presencia del pronombre enfatiza el carácter evidencial del enunciado, ya que el hablante se identifica en este caso con la fuente de la información: es él, quien tiene acceso a los hechos, es decir, quien percibe, razona y saca conclusiones.

En resumen, aunque los límites entre estos dos verbos resultan a primera vista ambiguos, se podría decir que činiti se es marcador evidencial con rasgos 
modales, mientras que izgledati es esencialmente evidencial. El primero, junto con la referencia a la fuente de la información, marca cierta dosis de inseguridad del hablante frente a lo dicho, el segundo dentro de su significado enfatiza el modo de acceso a la información.

\subsubsection{Las construcciones mora da (debe de) + verbo en forma finita y biće da (será que)}

La expresión mora da con un verbo en forma finita, codifica la información evidencial inferida, teñida de un matiz deóntico. El verbo morati (deber) en este uso aparece en forma impersonal, de modo que la persona se distingue a partir del predicado pospuesto a la conjunción $d a$ (que). A veces la construcción mora da va acompañada del verbo biti (ser): mora biti $d a$, con un matiz modal más acentuado. Las dos opciones, que alternan libremente, son marcadores evidenciales de tipo inferencial, como se puede observar de los ejemplos en serbio y sus versiones en español:

(17 a.)Mora da je važan čovek. [SrpKor]

Debe de ser un hombre importante. / Será un hombre importante.

(17 b.) Mora biti da je to rezultat kolektivnog napora. [SrpKor]

Debe de ser resultado de un esfuerzo colectivo. / Será resultado de un esfuerzo colectivo.

La construcción Mora da y su variante Mora biti da presentan el contenido proposicional como una conjetura expresada a partir de un proceso inferencial, pero, a diferencia de los marcadores analizados en 3.1.4, éste posee matiz deóntico, por lo que los ejemplos de (17) se pueden interpretar como supuestos o evidencias que obligan al hablante a derivar una inferencia y asignar a la proposición el mayor grado de veracidad posible. La construcción es equivalente a la perífrasis deber de con infinitivo y a algunas formas verbales en su uso modal, tema que planteamos en el siguiente apartado.

A diferencia de la anterior, el significado de la expresión semilexicalizada biće da (literalmente será que), formada por el verbo biti (ser) en forma impersonal, oscila entre un valor conjetural e inferencial, así que puede corresponder asimismo al uso de determinadas formas verbales, como señala el siguiente ejemplo:

(18)Biće da je to neka nameštaljka.

Será una trampa. / Quizás sea una trampa. 


\subsection{La evidencialidad en español}

La evidencialidad en español puede tener diversas realizaciones lingüísticas entre las cuales resulta de especial interés para un estudio comparativo serbio / español el uso de algunas formas verbales. Dadas sus particularidades sintácticas y semánticas, en el presente apartado me propongo analizar este tipo de recursos, ya que el sistema verbal constituye un área donde se presentan mayores diferencias entre estas dos lenguas.

El análisis realizado y los ejemplos citados en 3.1.2 señalan que, tanto en serbio como en español, existe cierta correlación entre la evidencialidad directa y el uso del presente y la evidencialidad inferida y el uso de los tiempos de pasado. Sin embargo, no siempre es posible establecer un paralelismo, ni siquiera relativo, ya que una coincidencia formal y denotativa no supone necesariamente una coincidencia en el nivel funcional y comunicativo, como demuestran algunos tiempos verbales: el futuro y el condicional (cada uno con su forma simple y compuesta) y el pretérito imperfecto.

El uso de dichas formas, en español así como en otras lenguas romances, puede transmitir, según Reyes (1994: 31) «precaución y cautela epistemológica», o sea, puede atenuar el carácter asertivo del enunciado, ofreciendo varias posibilidades de interpretación epistémica.

\subsubsection{El futuro}

El futuro es un tiempo verbal que está dotado de tanto potencial ilocutivo que su uso, en ambas lenguas, supera los límites de la simple referencia a un momento o período posterior al acto de enunciación. La orientación prospectiva y la incertidumbre en la realización de los eventos, que refleja su significado básico, le permiten desarrollar diferentes matices significativos y valores modales, que pueden suprimir su valor referencial por completo. Así ocurre en el ejemplo

(19)Todavía vive, tendrá unos 40 años. (CREA)

Još uvek je živ, verovatno ima oko 40 godina.

donde la forma tendrá no localiza el acontecimiento o la situación en un período posterior al acto de habla, sino que hacen referencia a un estado de cosas actual. Es decir, señala una conjetura (de ahí su nombre «futuro de conjetura», «futuro de probabilidad» 0 «futuro epistémico»), que el hablante expone a partir de sus reflexiones o conocimientos basados en indicios, expresando 
de esta manera un reducido grado de compromiso respecto del contenido proposicional.

Ahora bien, si se toma en cuenta que la evidencialidad es una categoría relacionada con la fuente de la información y el modo de acceso a la misma, está claro que su significado encaja perfectamente en los rasgos semánticos del futuro, es decir, en su carácter modal epistémico. Siguiendo a Escandell Vidal (2010: 22), el futuro conlleva la idea de que el hablante es la fuente u origen de la información y el modo de acceso es su propio razonamiento, por lo que esta forma verbal se puede definir como un verdadero marcador de evidencialidad inferida. Así empleado, no corresponde al futuro serbio, (como señalan las versiones españolas de (20)), sino que debe ser traducido con un verbo en presente, seguido de adverbios como možda, valjda, verovatno, equivalentes a quizás o probablemente o por la expresión mencionada biće da je (ver también el ejemplo (18) de 3.1.5)

La interpretación de «futuro de probabilidad» se extiende al futuro compuesto, sólo que el contenido comunicativo (la duda o la conjetura) se desplaza hacia el pasado, con lo cual el predicado en la versión serbia aparece en perfecto, acompañado de los adverbios de modo o se puede emplear la expresión biće da, como se observa en

(20) [...] el original habrá quedado, supongo, entre sus papeles póstumos. (CREA)

[...] original je verovatno ostao, pretpostavljam, među njegovim posthumno objavljenim spisima. / [...] biće da je original ostao $[\ldots]$

\subsubsection{El condicional}

El rasgo semántico más destacado del condicional es el hecho de que expresa un estado de cosas que sólo tiene significado si se relaciona, de manera explícita o implícita, con situaciones no actuales, pretéritas o hipotéticas (Nueva gramática de la lengua española, 2009: 1783). En efecto, es una forma subordinada al contexto, ya que el contenido proposicional de una oración, expresado por el condicional, siempre presupone una condición (Me gustaría leer este libro [si tuviera tiempo]), o un punto situado en el pasado que le sirva de referencia ([Dijo que] volvería la semana pasada/boy/mañana).

El condicional se define como «futuro del pasado», porque, como ya se ha sugerido, los eventos enunciados por él son posteriores a aquellos pasados 
respecto a los que determina su localización temporal. De su orientación prospectiva surge la idea de incertidumbre epistémica, lo que es justamente ese rasgo decisivo que le permite expresar valores evidenciales: esto es, marcar las informaciones obtenidas mediante un proceso inferencial o bien transmitirlas a partir de las palabras ajenas como señalan los siguientes fragmentos:

(21) - ¿Te acuerdas de Rosalía Perdomo? -la interrumpe Urania. -Rosalía Perdomo? -Lucinda busca, entrecerrando los ojos-. La verdad, no...

¡Ah, claro! ¿Rosalía, [...]? Más nunca se la vio por aquí. La mandarían al extranjero. (M. Vargas Llosa, La Fiesta del Chivo, 2000: 201). (22)A lo mejor, si le daba tiempo, tomaría una copa con ella en el mostrador del pub... (CREA)

Možda, ako bude imala vremena, popiće nešto sa njom za šankom paba...

Los verbos subrayados manifiestan un claro valor evidencial. La forma estaría leyendo presenta el enunciado como una conjetura expresada a partir de una explicación dada en la frase anterior. «Más nunca se la vio por aquí» es un indicio que lleva al hablante a concluir que «la han mandado al extranjero», o en otras palabras, que probablemente «la han mandado al extrajero». En este contexto mandarían es un marcador evidencial de tipo inferencial.

En cambio, tomaría alude al discurso de otra persona, o sea, manifiesta rasgos de evidencialidad referida (citativa). Sin embargo, este significado no se constituye sólo a partir del uso del condicional, sino que procede de su interacción con el contexto: en concreto, se realiza a través de una relación anafórica, que el condicional establece con un acto de habla implícito: [Dijo que] tomaría.

El condicional compuesto comparte asimismo con el simple el valor epistémico, sólo que designa una situación anterior a la enunciada por éste, como demuestra

(23)Habría pasado una hora, cuando el vigilante creyó oír pasos [...]. (Crea)

Verovatno je prošao jedan sat, kada je čuvar čuo korake [...].

Ahora bien, la cuestión que se plantea es cómo se expresan en serbio los efectos pragmático-discursivos, producidos por el condicional español, dado que 
esta forma dentro del sistema verbal serbio se considera modo hipotético, por lo que puede coincidir sólo con el condicional de cortesía en los enunciados de tipo Hteo bib da vas zamolim nešto (Querría pedirle algo) o con su uso en las oraciones condicionales eventuales e irreales: Pomogla bib ti da imam vremena (Te ayudaría si tuviera tiempo). El significado conjetural, sin embargo, tiene que ser parafraseado mediante recursos léxicos (adverbios de modo probablemente, seguramente, etc.), que siguen al predicado, empleado en perfecto (el ejemplo 22.). En cambio, cuando el condicional funciona como marcador de evidencialidad referida, que en realidad corresponde al discurso indirecto libre o, según Reyes (1994), a cita implícita o encubierta, equivale al futuro simple, como se observa de la versión serbia del mismo ejemplo.

\subsubsection{El pretérito imperfecto}

El pretérito imperfecto de indicativo constituye asimismo un recurso propicio para expresar el significado evidencial. Sin embargo, a diferencia de las formas mencionadas, que marcan evidencialidad inferencial, el pretérito imperfecto (hasta cierto punto semejante a la variante descrita del condicional) puede funcionar como marcador de evidencialidad referida. De ahí que reciba el nombre de «imperfecto citativo» o «de cita» (Nueva gramática de la lengua española, 2009: 1750).

El pretérito imperfecto se caracteriza por dos rasgos fundamentales: por un lado, es un tiempo relativo, es decir, no autónomo, que precisa de un punto de referencia, anterior al momento de habla como condición necesaria para la realización de su significado; por otro, es un tiempo imperfectivo, presenta las situaciones en su curso, sin aludir a su comienzo y fin (Nueva gramática de la lengua española, 2009: 1743). Estos dos rasgos son la base de su uso citativo, ya que le permiten orientarse hacia diferentes perspectivas temporales (pretéritas, prospectivas o actuales) y vincularse a un punto de referencia, de forma expresa o tácita.

El pretérito imperfecto de cita es un pretérito con valor prospectivo. Su presencia en el enunciado produce un efecto ambiguo, pues marca dos informaciones al mismo tiempo: una explícita, que se asigna al emisor del enunciado y otra implícita, que alude a la fuente de la información, es decir, al enunciado de un hablante distinto al emisor. Este «juego» de perspectivas o «confluencia de voces» se manifiesta en el siguiente diálogo:

(24) ¿جTienes alguna noticia de Juan? -Se iba de viaje mañana.

-Imaš li nekih vesti od Huana? -[Navodno] sutra putuje. 
Al utilizar el imperfecto, el hablante remite a un evento posterior al acto de habla y, además, lo relaciona anafóricamente con otra situación de enunciación implícita, que se podría marcar con un verbo de lengua u otro elemento introductorio:

$(25)[D i j o$ que] se iba de viaje mañana. (Podía haberlo dicho el mismo Juan u otro locutor).

[Rekao je] sutra putuje.

El imperfecto citativo expresa distancia, o sea, un menor grado de compromiso del hablante frente al enunciado, permitíendole atribuir la responsabilidad por las palabras enunciadas a otra u otras personas. La sustitución del imperfecto por el presente anula el valor citativo del enunciado. «Se va de viaje mañana» (Sutra ide na put) comunica un hecho, pero no presupone ninguna información relativa a la fuente de lo comunicado.

En lo que atañe a su traducción al serbio, se ofrecen dos posibilidades, de las cuales ninguna es el imperfecto, ya que esta forma se mantiene en la actualidad sólo en el uso literario. Así pues, el imperfecto de cita, ilustrado en (24) se puede expresar mediante un recurso léxico, el marcador navodno, o empleando un verbo de lengua explícito, o bien se puede derivar simplemente a partir de la situación comunicativa. De ahí que no se establezca prácticamente ninguna distinción formal entre los enuciados «Se iba de viaje mañana» $\mathrm{y}$ «Se va de viaje mañana»; los dos contienen en serbio el predicado en presente, seguido de un complemento adverbial, que es el que localiza la acción en el futuro. No obstante, hay casos de coincidencia. El imperfecto español es análogo al imperfecto serbio en las oraciones interrogativas, cuando el hablante evoca una información que le ha sido accesible y conocida, pero de la que no se puede acordar en el momento de la enunciación:

(26)¿Cómo se llamaba tu amiga? Kako se zvaše tvoja prijateljica?

¿Y cuándo era la reunión? A kad beše sednica?

El pretérito pluscuamperfecto asimismo puede funcionar como marcador de cita implícita, gracias a su condición de tiempo relativo, o sea, a su naturaleza deíctica (anafórica), que le permite relacionar dos situaciones comunicativas: la del emisor del enunciado y la del hablante, cuyo enunciado se transmite. El pretérito pluscuamperfecto se traduce casi siempre con el perfecto serbio, pero cuando adquiere valor citativo, éste no tiene una realización específica, sino que se desarrolla como un efecto adicional de la situación comunicativa, según ilustra el siguiente ejemplo: 
(27)Volvió asustado: no había encontrado a nadie en casa.

Vratio se uplašen: nikoga nije našao kod kuće.

\section{Observaciones finales}

La evidencialidad es una categoría semántica universal, perteneciente a todas las lenguas del mundo, pero con diferentes realizaciones formales. La finalidad principal de este estudio comparativo ha sido observar los rasgos comunes y distintivos en la codificación de este fenómeno en serbio y en español y presentar diversas posibilidades que existen a la hora de traducir de una lengua a otra. El análisis realizado a partir de los ejemplos extraídos del CREA y de SrpKor ha demostrado que los procedimientos de codificación, tanto en serbio como en español, se pueden manifestar en dos niveles: en el nivel léxico y en el nivel funcional, ambos en interacción con los parámetros pragmático-discursivos.

La codificación de la evidencialidad en el nivel léxico comparte, hasta cierto punto, características comunes, es decir, se presentan rasgos análogos en el uso de los marcadores adverbiales, de los verbos de percepción en las oraciones subordinadas, así como de los verbos izgledati y činiti (parecer), si bien en este nivel asimismo hay casos, en que la traducción no supone simple reproducción del significado denotativo o de la forma gramatical, sino que requiere una interpretación más completa que tome en consideración los factores contextuales o la situación comunicativa real.

Frente a este relativo paralelismo, presentan diferencias en el uso los marcadores mora (biti) da y biće da y las categorías verbales de tiempo y aspecto.

Las expresiones semilexicalizadas, de significado ambiguo, que oscila entre un matiz modal y evidencial, adoptan en español distintas formas: la primera, mora (biti) da coincide con la perífrasis deber de con infinitivo, con el futuro de probabilidad (simple y compuesto) o bien con los adverbios de modo (probablemente, quizás y sus sinónimos) adjuntos a un predicado, mientras que la segunda biće da se expresa también con una de las formas del futuro de probabilidad (ver 3.1.5).

Los rasgos distintivos más patentes se manifiestan cuando la expresión de la evidencialidad está relacionada con la flexión verbal, porque los sistemas verbales de serbio y español, si bien presentan correspondencia formal e incluso cierto grado de semejanza con respecto al uso, se diferencian por el 
funcionamiento de las categorías que forman su paradigma. A saber, el verbo serbio está marcado por el aspecto, de ahí que sean posibles los usos descritos en 3.1.2: el verbo imperfectivo en presente y el perfectivo en aoristo (un pasado próximo al presente) codifican la información evidencial perceptual; el verbo imperfectivo en perfecto codifica la información evidencial inferencial, mientras que el perfectivo marca la información evidencial de tipo perceptual. En realidad, en todos estos casos el portador del significado es el aspecto. Las formas correspondientes son el presente, pretérito perfecto simple y el compuesto.

Sin embargo, el rasgo dominante del tiempo verbal en español es su naturaleza deíctica, lo que posibilita los usos evidenciales inferenciales y citativos descritos en 3.4, usos cuyos significados en serbio se deben expresar mediante recursos léxicos (el adverbio navodno) o a través de una oración en estilo indirecto o bien se pueden identificar, simplemente, a partir del contexto.

El análisis de los recursos gramaticales y léxicos de la evidencialidad realizado en este trabajo representa sólo un aspecto de un tema muy complejo y extenso, que puede y debe ser planteado con mayor profundidad y detalle dentro de un marco interdisciplinar (sociolingüístico, antropológico, estilístico, etc.).

\section{Bibliografía}

Aikhenvald, A. (2004): Evidentiality. Oxford: Oxford University Press.

AALE, Asociación de Academias de la Lengua Española (2009): Nueva Gramática de la Lengua Española, Vol. II. Madrid: Espasa.

Bermúdez Wachtemeister (2005): Evidencialidad. La codificación Lingüística del punto de vista, Doctoral dissertation. Department of Spanish, Portuguese and Latin American Studies. Stockholm Universitet.

Chafe, W. y Nichols (eds.) (1986): Evidentiality: The Linguistic Coding of Epistemology. Norwood, NJ: Ablex.

Dendale, P., y Tasmowsky L. (2001): «Introduction: Evidentiality and related notions». Journal of Pragmatics, 33, 339-348.

Escandell Vidal, M. V. (2010): «Futuro y evidencialidad». Anuario de Lingüística Hispánica, 26, 9-34.

Escandell Vidal, M. V. y Leonetti, M (2005): «Polifonía y flexión verbal». En P. Albalá et al. (eds.): Lingüística y Filología. Homenaje a Antonio Quilis. Madrid: CSIC, 447-465. 
Estrada, A (2013): Panorama de los estudios de la evidencialidad en el español. Buenos Aires:Teseo.

Plungian V. A. (2001): «The place of evidentiality within the universal grammatical space». Journal of Pragmatics, 33, 349-357.

Popović, Lj. (2010): Kontrastivna gramatika srpskog $i$ ukrajinskog jezika: taksis $i$ evidencijalnost. Srpska akademija nauka i umetnosti, 2012.

Pihler Ciglič, Barbara (2014): «Partículas modales con valor epistémico y evidencial en esloveno y sus equivalencias en español». Estudos linguísticos, 10, 219-235.

REAL ACADEMIA ESPAÑOLA (2009): Nueva gramática de la lengua española, Madrid: Espasa-Calpe.

Ristić, S. (2009): Modification of meaning and lexical modifiers in Serbian. Serbian language institute of SASA.

Rajić, J. (2012): «Estrategias de evidencialidad en serbio y en español». Srpski jezik 27, Beograd, 463-472.

Rajić, J. (2012): «Polifonía y formas verbales». Verba Hispanica, Ljubljana, 20/2, 295-237.

Reyes. G. (1990): «Tiempo, modo, aspecto e intertextualidad». Revista Española de Lingüística, 1, 17-55.

Reyes, G. (1993): Los procedimientos de cita: estilos directos e indirectos. Madrid: Arco Libro.

Reyes, G. (1994): Los procedimientos de cita: citas encubierta y ecos. Madrid: Arco Libros.

Trbojević-Mološević, I. (2004): MODALNOST, SUD, ISKAZ. Epistimička modalnost u engleskom i srpskom jeziku. Beograd: Filološki fakultet.

Willett, T. (1988): «A cross-linguistic survey of the grammaticalization of evidentiality». Studies in Language, 12, 51-97.

\section{Fuentes}

KORPUS SAVREMENOG SRPSKOG JEZIKA (5.02.2015)

REAL ACADEMIA DE LA LENGUA ESPAÑOLA. BANCO DE DATOS (CREA). Corpus de referencia del español actual http://www.rae.es $(5.02 .2015)$

Vargas Llosa, M. (2000), La fiesta de cbivo. Madrid: Alfaguara. 
Jelena Rajić

University of Belgrade

\section{Contrastive analysis of the expression of evidentiality in Spanish and Serbian}

Keywords: Serbian / Spanish contrastive analysis, evidentiality, modality, evidential markers.

This paper investigates the concept of evidentiality from a cross linguistic perspective, based on the comparison of two geographically and typologically distant languages, Serbian and Spanish.

The study aims to give insight into pattering of lexical, grammatical and discursive strategies in the expression of evidential meanings, to draw distinctions and note similarities in its use and to facilitate a comparative view of the devices employed in both languages. The investigation is based on Corpus of Contemporary Serbian Language and Corpus of Spanish Language.

Given the contrastive nature of the study, different possibilities of translating all linguistic expressions with evidential value are discussed in detail, such as in their lexical and grammatical so in their discursive realization. 
Jelena Rajić

Univerza v Beogradu

\section{Primerjalna analiza izražanja evidencialnosti v srbščini in španščini}

Ključne besede: španščina/srbščina, primerjalna analiza, evidencialnost, modalnost, označevalci evidencialnosti

Prispevek obravnava pojav evidencialnosti z medjezikovnega vidika, oziroma z vidika primerjave dveh geografsko in tipološko oddaljenih jezikov, srbščine in španščine.

Namen študije je omogočiti vpogled v vzorčenje besednih, slovničnih in diskurzivnih strategij pri izražanju evidencialnih pomenov, orisati razlike in stičišča $\mathrm{v}$ njihovi rabi ter $\mathrm{z}$ vidika primerjave podati pregled sredstev, ki jih uporabljata oba jezika. Raziskava temelji na korpusih sodobnega srbskega jezi$\mathrm{ka}$ in sodobne španščine.

V okviru primerjalne študije so podrobno obravnavane predvsem različne izrazne možnosti evidencialnosti v prevodih, tako glede na njihove leksikalne kot tudi slovnične in besedilne vloge. 